\title{
Trends in licence approvals for ophthalmic medicines in the United Kingdom
}

\author{
Peter J. Morgan-Warren ${ }^{1}$ Jiten B. Morarji ${ }^{1}$
}

Received: 9 August 2019 / Revised: 15 November 2019 / Accepted: 22 November 2019 / Published online: 3 January 2020

(C) The Author(s), under exclusive licence to The Royal College of Ophthalmologists 2020

\begin{abstract}
Objectives The grant of marketing authorisation (MA) for new medicines requires comprehensive assessment by regulatory authorities. This study sought to identify ophthalmic medicines granted United Kingdom MA and consider trends in licence approvals.

Methods This retrospective study reviewed published lists of products granted MA by the UK Medicines \& Healthcare products Regulatory Agency between January 2001 and December 2018, inclusive. Eye drops and medicinal products intended for ophthalmic use were identified. All regulatory data sources consulted are in the public domain. Data analyses were descriptive.

Results A total of 295 MAs were issued for ophthalmic products between 2001 and 2018, inclusive. Of these 229 (78\%) were for single-active substances and $66(22 \%)$ fixed-dose combination (FDC). Approvals for products with single-active substance included ocular hypotensives $(115 ; 50 \%)$, antibiotics $(48 ; 22 \%)$, allergy medicines $(30 ; 13 \%)$, lubricants $(18 ; 8 \%)$ and anti-inflammatories $(11 ; 5 \%)$. Approvals for FDCs were predominantly ocular hypotensives $(56 ; 85 \%)$, with timolol combined with carbonic anhydrase inhibitors $(27 ; 48 \%)$ and prostaglandin analogues $(26 ; 46 \%)$ accounting for the majority of glaucoma FDCs. Other FDCs were approved for antibiotic/inflammatory $(5 ; 7.5 \%)$, pupillary mydriasis $(2 ; 3 \%)$, allergy $(2 ; 3 \%)$ and ocular surface lubrication $(1 ; 1.5 \%)$ products. A median of 16 licences were approved per year (range 7 [2005] to 35 [2011]).

Conclusions The majority of MAs granted were for single-agent products, particularly ocular hypotensives and antibiotic preparations. Most products were generic versions of well-established active substances. A trend for increased approvals for FDCs is evident, particularly for the treatment of raised IOP.
\end{abstract}

\section{Introduction}

Before a medicine can be placed on the market, it must be granted a Marketing Authorisation (MA) by a regulatory authority after a thorough review of pharmaceutical, preclinical and clinical data. In the United Kingdom, the Medicines and Healthcare products Regulatory Agency (MHRA) is the national competent authority responsible for the assessment of applications. The grant of a MA occurs when it is deemed that the benefit-risk balance for the product is positive. Regulatory agencies across the European Union (EU) are

Peter J. Morgan-Warren

peter.morgan-warren@mhra.gov.uk

1 Medicines \& Healthcare products Regulatory Agency, London, UK allied to the European Medicines Agency (EMA) that coordinates the European regulatory network [1,2].

For ophthalmic medicines, as with all medicinal products, grant of a MA is usually achieved by via one of four main routes:

(1) National approval by the competent authority of an individual country.

(2) Mutual Recognition Procedure (MRP): a product that is approved nationally is subsequently approved by one or more additional EU Member States after review and acceptance of the original national application dossier.

(3) Decentralised Procedure (DCP): a product is approved in a group of $(\geq 2)$ Member States after review of the application dossier.

(4) Centralised Procedure: a product is formally assessed by two countries ('Rapporteurs') and their assessment 
is then 'peer' reviewed by the additional Member States, resulting in grant of an EU-wide MA once positive benefit-risk balance is agreed.

The Centralised Procedure is mandatory for certain types of indications (e.g., diabetes, cancers) and products including biologics, advanced technology products such as gene therapies, and medicines for rare diseases [2]. For ophthalmic medicines falling into the above categories (e.g., biologics, such as anti-VEGF agents), assessment through the Centralised route is compulsory. For other products companies may choose to apply through this route for a pan-European MA [3], although many products are approved for marketing at a national level or in groups of countries through the decentralised and mutual recognition regulatory procedures. The procedures and legal requirements for MA applications in the EU in are laid out in Directive 2001/83/EC and in Regulation (EC) No. 726/ 2004. Applications for MA can be made in accordance with: (i) Article 8(3), so-called 'full-dossier' applications for which full results of pharmaceutical testing, pre-clinical tests and clinical trials are required; (ii) Article 10, so-called 'abridged' applications which refer in part to data from a 'reference' product, and includes Article 10(1) 'generics', Article 10(3) 'hybrid' products and Article 10(4) 'biosimilars'; (iii) Article 10a 'well-established use' applications that are supported by bibliographic literature; (iv) Article $10 \mathrm{~b}$ applications relating to new fixed combinations of active substances; and (v) Article 10c 'informed consent' applications [4]. Detailed reviews on European pharmaceutical regulations [5], and comparison with regulations in other jurisdictions $[6,7]$ are available elsewhere.

With longer life expectancy and earlier detection of ophthalmic disease, there is a continued requirement for clinical development of therapies targeting different stages of treatment, from preventive measures to treatment of established ophthalmic disease with novel therapeutic agents [8-10]. Furthermore, pharmacoeconomic considerations surrounding affordability of medicines ensure a continued and increasing demand for the development of generic medicines, especially in public-funded health systems [10-12].

The aim of this work is to identify the ophthalmic medicines granted a UK MA, excluding centrally authorised pan-EU approvals, and consider trends in licence approvals for these products.

\section{Methods}

This study is a retrospective analysis of published data pertaining to the UK grant of MAs by the MHRA for ophthalmic medicines. All sources and data consulted are in the public domain.

A list of MAs granted by month is published on the MHRA website [13] from January 2014. Previous lists of granted licences are available on the UK National Archives website [14], from January 2001 to October 2014, inclusive. Medicinal products approved by the Centralised Procedure though the EMA are not included in the MHRA published lists of granted licences and are not considered in this report. For discussion on these products, other references are available [3].

The published lists of granted UK licenses on the MHRA website were reviewed from January 2001 to December 2018, inclusive, to identify ophthalmic medicines. The following data fields are included on the monthly lists and were extracted for each identified ophthalmic product: PL (product licence) number; date of grant of MA; MA holder; licensed name of product; active ingredient and quantity (strength). Details of the legal basis of approval (the Article of Directive 2001/83/EC, under which the application is filed), and whether products were approved on a national basis in the UK or as part of a DCP or MRP are not included in the published product approval lists. Data were recorded on a spreadsheet (MS Excel), and all analyses were descriptive.

\section{Results}

A total of 295 MAs were issued between January 2001 and December 2018, inclusive, comprising 229 (78\%) approvals with a single-active substance and 66 (22\%) fixed-dose combination (FDC) licences. A summary of approved licences between 2001 and 2018 by drug class is given in Table 1 for single agents and Table 2 for FDC products.

A graphical summary of the number of approvals by year is given in Fig. 1. A median of 16 licences were approved per year, with range 7 (2005) to 35 (2011).

The majority of approvals for products with single-active substance were for ocular hypotensive products $(115 ; 50 \%)$. Antibiotics $(48 ; 22 \%)$, allergy medicines $(30 ; 13 \%)$, lubricants $(18 ; 8 \%)$, and anti-inflammatories $(11 ; 5 \%)$ were the other main classes of agents approved (Fig. 2).

The majority of approvals for FDC products were for ocular hypotensive products $(56 ; 85 \%)$, with the betablocker timolol in combination with carbonic anhydrase inhibitors $(27 ; 48 \%)$ and prostaglandin analogues $(26 ; 46 \%)$ accounting for the vast majority of approved licenses for glaucoma FDCs. The remaining approvals for FDCs were for antibiotic/inflammatory $(5 ; 7.5 \%)$, pupillary mydriasis $(2 ; 3 \%)$, allergy $(2 ; 3 \%)$ and ocular surface lubrication (1; $1.5 \%$ ) (Fig. 3). 


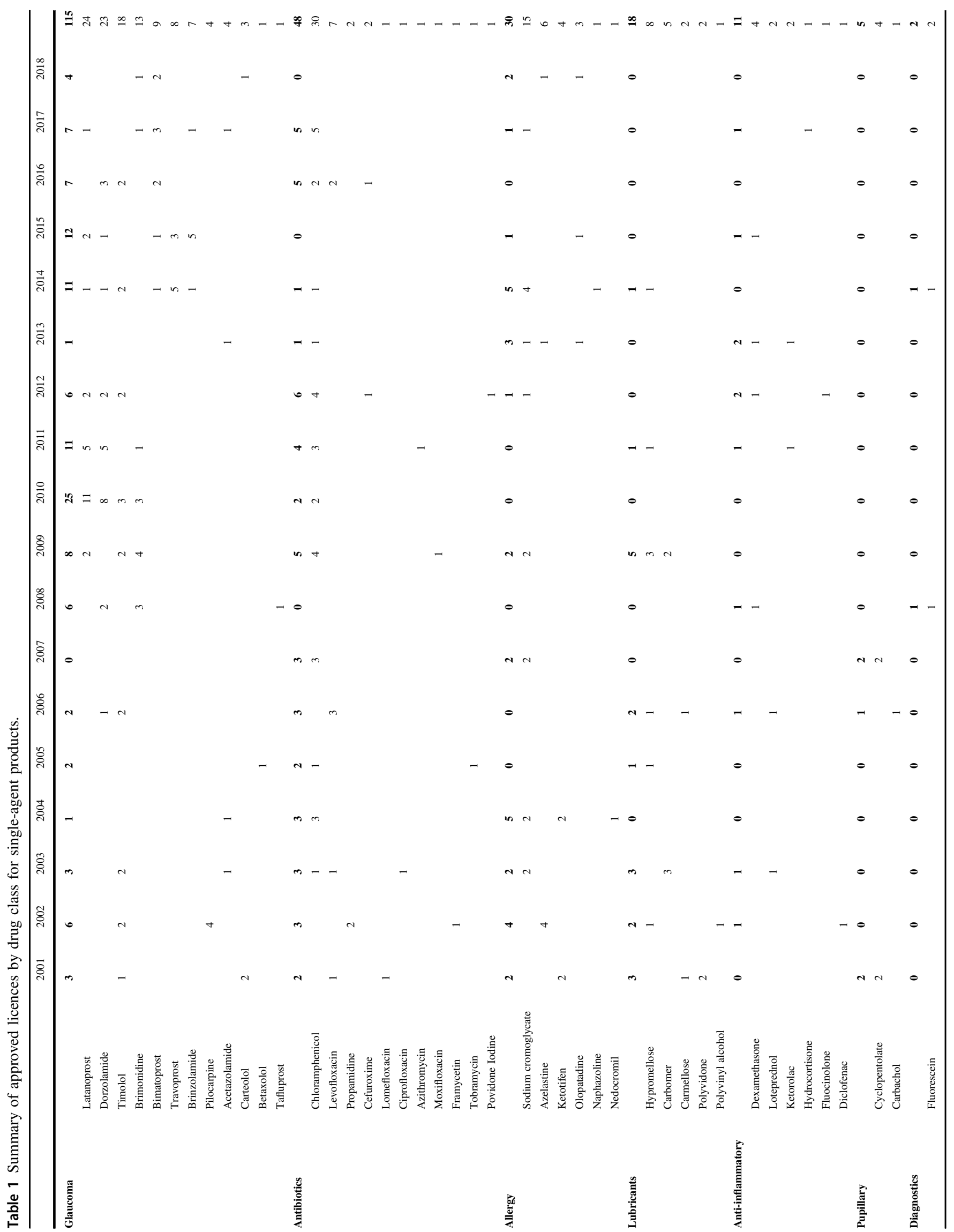



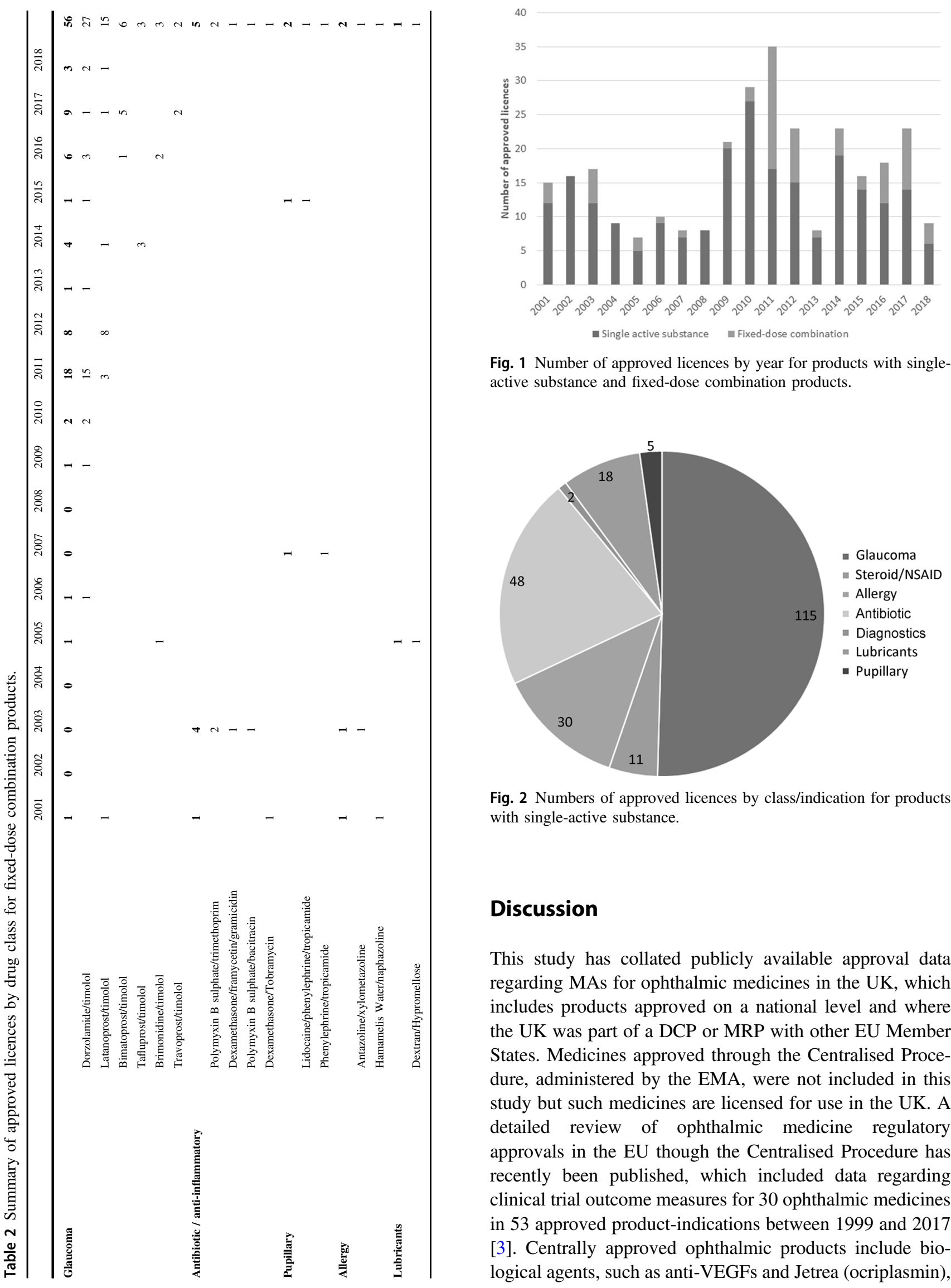

Fig. 1 Number of approved licences by year for products with singleactive substance and fixed-dose combination products.

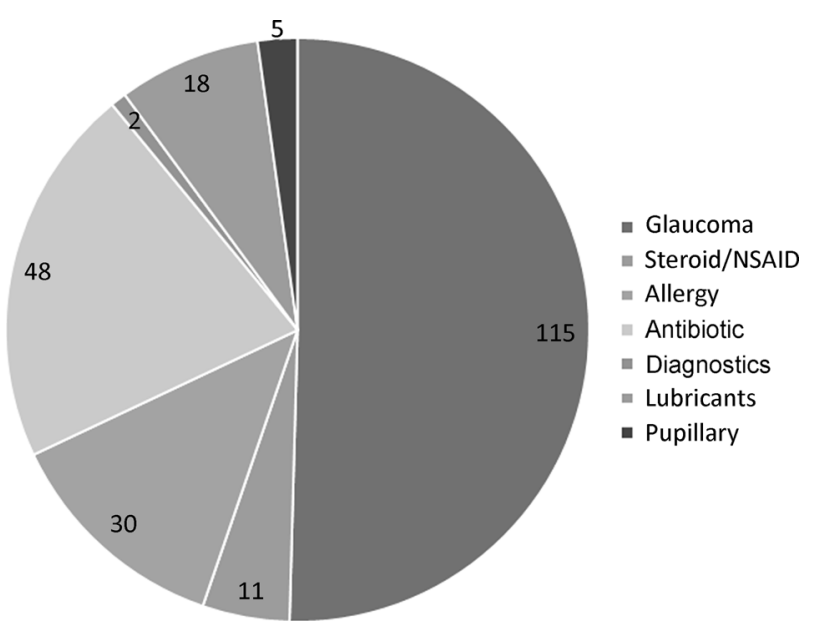

Fig. 2 Numbers of approved licences by class/indication for products with single-active substance.

\section{Discussion}

This study has collated publicly available approval data regarding MAs for ophthalmic medicines in the UK, which includes products approved on a national level and where the UK was part of a DCP or MRP with other EU Member States. Medicines approved through the Centralised Procedure, administered by the EMA, were not included in this study but such medicines are licensed for use in the UK. A detailed review of ophthalmic medicine regulatory approvals in the EU though the Centralised Procedure has recently been published, which included data regarding clinical trial outcome measures for 30 ophthalmic medicines in 53 approved product-indications between 1999 and 2017 [3]. Centrally approved ophthalmic products include biological agents, such as anti-VEGFs and Jetrea (ocriplasmin), 


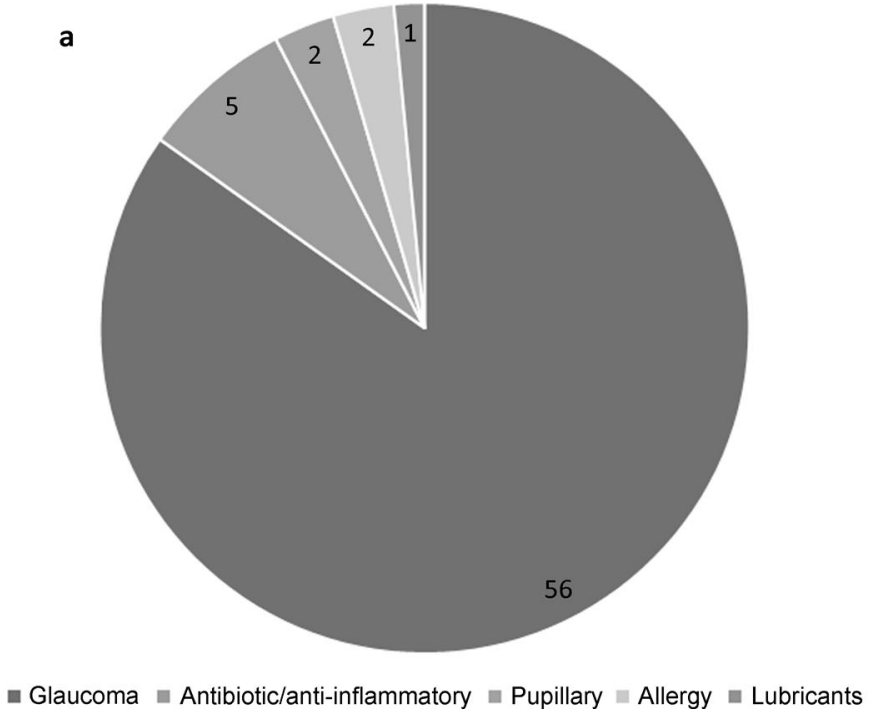

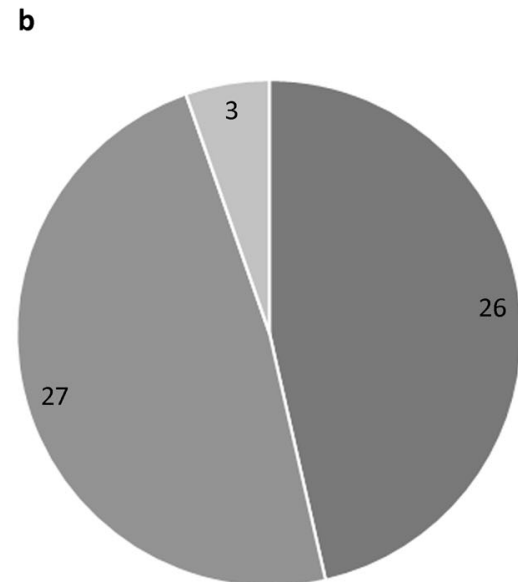

$\because \mathrm{BB}+\mathrm{PGA}=\mathrm{BB}+\mathrm{CAl} \equiv \mathrm{BB}+\mathrm{alpha}$

Fig. 3 Numbers of approved licences by class/indication for fixed-dose combination (FDC) products: (a) total FDC approvals; (b) ocular hypotensive products. BB beta-blocker, PGA prostaglandin agonist, alpha alpha-adrenoreceptor agonist, CAI carbonic anhydrase inhibitor.

several ocular hypotensive agents, such as Travatan (travoprost) and Lumigan (bimatoprost), FDC products such as Ganfort (bimatoprost/timolol FDC) and Simbrinza (brinzolamide/brimonidine), as well as other products for a number of ophthalmic indications [3]. To the authors' knowledge, the current report is the first such study detailing trends in UK approvals for ophthalmic medicines.

\section{Single agents}

The majority of approvals were for single-agent medicinal products, particularly ocular hypotensive medicines. The most common such agent reported is latanoprost and was first approved in Europe in 1996 as Xalatan (Pfizer). Latanoprost represented a new class of ocular hypotensive for treatment of raised intraocular pressure (IOP) and, as with all new active substances, is granted a period of market protection in the EU before 'generic' versions can be approved [4]. The regulatory protection of market exclusivity enables innovators a period of 10 years to recoup some of the large investment in clinical development before being exposed to the market forces of generic versions of the same active substance. This explains the approval of latanoprost products from 2009 onwards and similarly the later approval of products containing, for example, brinzolamide, travoprost, and bimatoprost that were originally approved in Europe via the Centralised Procedure as Azopt (Novartis), Travatan (Novartis), and Lumigan (Allergan) in 2000, 2001, and 2002, respectively [3]. With increasing global prevalence of glaucoma there is a considerable clinical and economic burden [10, 15], especially for public health systems, with a significant expenditure on medication and an attractive market for pharmaceutical companies. Newer, more effective and better tolerated, but more costly agents are replacing older and less expensive medications [16], and generics manufacturers are keen to market their own versions when entitled after expiry of market protection periods. Similarly, the anti-allergy medicine olopatadine was originally centrally approved ('Opatanol'; Novartis) in 2002, hence the first 'generic' version approved in the UK in 2013 when the period of market exclusivity has expired.

Many of the single-agent products granted licences were for well-established active substances, for example the betablocker timolol and antibiotics such as chloramphenicol and levofloxacin. Ophthalmic clinical use of these agents in the UK is widespread, hence there is considerable commercial incentive for companies to seek licences for generic versions of these products to enter the market. Chloramphenicol remains a popular first-line broad spectrum topical antibiotic, especially in the UK where safety concerns about potential blood dyscrasias that limit its use in North America are not considered a major concern for short-term use of topical preparations of the drug in the UK $[17,18]$. Topical anti-allergy medicines such as sodium cromoglycate and azelastine are commonly used in many countries [19].

In general, for products containing active substances which are well-established in clinical use, it is not usually necessary for applicants to submit 'full-dossier' applications under Article 8(3), which require comprehensive pharmacological, pre-clinical, and clinical trial data, and would be necessary for medicines containing new active substances. Approval of established agents can usually be granted by 
abridged applications, on the basis of pharmaceutical equivalence in relation to its physiochemical characteristics (qualitative and quantitative composition) with an already approved 'reference product' [20]. Although often referred to as 'generic' medicines, eyedrop formulations of wellestablished active substances are more correctly referred to as 'hybrid' medicines, as the European regulatory framework reserves the former terminology for medicines where systemic bioequivalence can be demonstrated and approval is granted under Article 10(1) of Directive 2001/83/EC. As eyedrops are locally applied and locally acting formulations, they cannot strictly meet the regulatory definition of generic medicines, and are generally approved in accordance with Article 10(3) and hence the term 'hybrid' is preferred by regulators. The published lists of authorised medicines that were consulted for this study do not report the legal basis of approval or type of data submitted in support of the MA application. Topical medicines with well-known active substances are likely to have been approved under Article 10(3) on the basis of either: (i) data demonstrating pharmaceutical equivalence to the already approved reference medicinal product, i.e., product as aqueous solution and containing the same concentration of the same active substance with no significant differences in excipients likely to affect pharmaceutical properties; or (ii) comparative clinical pharmacodynamic/therapeutic equivalence studies that demonstrate comparable clinical efficacy and safety of the new product with respect to the innovator product. For ophthalmic hybrid products, demonstration of pharmaceutical equivalence against the reference product is usually sufficient for approval of aqueous solutions, although other formulations such as ophthalmic suspensions would normally be expected to be supported by additional clinical studies [21, 22].

The regulatory approval process aims to ensure that generic/hybrid medicines are interchangeable with brandname drugs and so patients should expect comparable levels of efficacy and safety if switched between products. For example, a latanoprost $0.005 \%$ ophthalmic solution product (unbranded) has been demonstrated to be non-inferior to the innovator product, Xalatan (Pfizer), at 12 weeks in a randomised, double-masked multicentre study of 184 glaucoma/OHT patients in Italy, with a comparable safety profile [23]. A key advantage of generic/hybrid medicines is the potential for cost saving with generic products. For latanoprost alone, the reducing price of products and increased generic prescribing practices are reported to save the NHS in excess of $£ 32$ million per annum [24]. However, potential disadvantages associated with generic/hybrid eyedrops are the differences in packaging and presentation or storage instructions which may interfere with an established patient familiarity with the originator product. This may especially be the case if the delivery system (multi- dose bottle or single use vial) varies slightly from product to product, and certain groups of patients (e.g., elderly or those with disability) may take time to adapt to administer their medication from some bottles initially if they are not familiar with the delivery device. Patients may also rely on a specific compliance aid for drop administration that may not be compatible with all products $[24,25]$.

Although it is clear that many of the products approved were for active substances already in well-established clinical use (e.g., timolol, chloramphenicol) and/or were new preparations of actives originally approved centrally (e.g., bimatoprost), some significant new products were not approved centrally and were thus identified in this study. Iluvien (fluocinolone acetonide; Alimera Sciences Limited) $190 \mu \mathrm{g}$ intravitreal implant was initially approved in the UK in 2012 for the treatment of vision impairment associated with chronic diabetic macular oedema considered insufficiently responsive to available therapies. The product was licensed through the decentralised procedure (DCP) along with Austria, France, Germany, Italy, Portugal and Spain. It was subsequently approved in a number of other EU countries (Belgium, Czech Republic, Denmark, Finland, Luxembourg, Norway, Poland, Republic of Ireland, Sweden and Netherlands) via a mutual recognition process in 2014 [26]. Although fluocinolone acetonide is not a new active substance, Iluvien is an innovator product for ophthalmology as a new route of administration for this corticosteroid, and was approved under Article 8(3) on the basis of a comprehensive assessment of a full dossier of pharmaceutical, toxicological and clinical efficacy and safety data with a conclusion of positive benefit-risk balance. From a clinical perspective, assessment of new medicines usually requires substantive data from two pivotal clinical trials that demonstrate clear efficacy and a favourable safety profile, although data from a single pivotal phase III study may be considered sufficient if particularly compelling with respect to internal and external validity, clinical relevance, statistical significance, data quality, and internal consistency [27]. Iluvien has recently in 2019 received approval for the additional indication of prevention of relapse in recurrent non-infectious uveitis affecting the posterior segment of the eye [26]. Aprokam (cefuroxime; Thea Pharmaceuticals Ltd) $50 \mathrm{mg}$ powder for solution for injection was approved in the UK in 2012 for intracameral antibiotic prophylaxis of postoperative endophthalmitis after cataract surgery, through a DCP in which the primary assessment was conducted by Sweden [28]. The clinical efficacy and safety aspects of this application were supported by reference to published literature, such as the pivotal ESCRS study [29], rather than by studies specifically undertaken by company. At the time of approval, this became the only licensed product in the UK for intracameral prophylaxis, thereby overcoming a major barrier to widespread adoption of 
intracameral cefuroxime $[30,31]$. An additional product, Ximaract (cefuroxime; Bausch \& Lomb U.K Limited) 50 $\mathrm{mg}$ powder for solution for injection, was similarly approved in 2016 [32]. Both Aprokam and Ximaract exemplify products obtaining MA by reference to bibliographic data, so-called 'Article 10a' approvals [20, 28, 32]. To be eligible for approval via this route, it must be demonstrated that the medicine has been used for more than 10 years with a well-established efficacy and safety profile for the stated indications. A comprehensive scientific discussion for the quality, efficacy and safety of the medicine must be provided in addition to an extensive critique of the literature for its use in the claimed indications (all of which can be sourced from the scientific literature) before a positive benefit-risk and grant of MA can be awarded $[4,20]$. An advantage of the Article 10a approval route is that it is not compulsory for the company to conduct their own clinical studies in order to demonstrate efficacy/safety. However, this can still be a challenging route to obtaining MA, since published clinical trials and data available on well-established active substances are often old and are limited by retrospective data analyses to provide a sound scientific justification for the use of the proposed new product [33]. Furthermore, it can be challenging for the company to demonstrate comparability between its product (for quality, safety and efficacy) and those cited in the literature.

Ocular lubricants accounted for $8 \%$ of approvals, with the majority of these products gaining MA before 2010 . Historically, artificial tears or ocular lubricants have been considered as medicinal products and regulated under the European medicines legislation but, with the more recent introduction of medical devices regulations and amendments to the definitions of medicinal products and devices, such products are now generally classified under devices legislation along with contact lenses and lens care solutions [34-36]. Although it is clear that ocular lubricant eyedrops are intended for the prevention/treatment of symptoms of dry eye, the principle mechanism of action of these products cannot usually be attributed to 'pharmacological, immunologic or metabolic means', and thus consequently they are considered as devices rather than medicines for regulatory purposes, and often readily available 'over-the-counter'. Disparity between the regulatory requirements for approval between devices and medicines has led some to question the impact on quality standards [37]. Medicated artificial tears remain under the jurisdiction of the medicines regulations $[20,38]$.

\section{Combination agents}

FDC products are formulations that contain two or more active ingredients in a single dose. According to the EMA, potential advantages of FDC products are when the combination improves clinical response in patients with inadequate response to monotherapy, has a greater overall effect and/or is more rapidly effective; or where the combination improves overall safety, due to one active substance counteracting the adverse drug reactions of another or by combining doses that are sub-therapeutic when used in monotherapy [39].

The majority of MA approvals for FDCs were for ocular hypotensive products, which all included the wellestablished ocular hypotensive timolol in combination with other approved agents. In glaucoma, where many patients are dependent on several medications for optimal IOP control, compliance with medication is critical and often problematic [40]. FDC medicinal products offer the potential for simplified administration where the combination of active substances is already recognised as efficacious and safe [39].

A 2015 study reviewed FDC approvals for all therapeutic areas by the United States Food and Drug Administration (FDA) between 1980 and 2012, and reported that of 901 new drugs, FDC products accounted for $3.5 \%$ of FDAapproved new molecular entities (NMEs, i.e., including one or more active substances that had not previously been approved) [41]. In addition, 117 non-NME FDC drugs (new combinations containing only already-marketed drugs) were approved, with a clear trend for increasing numbers of approval: on average 1.2 approvals per year in the 1980s to 5.9 per year in the 2000s and 7.0 per year in the period 2010-2012. The data in the present UK study also show a general trend for increasing FDC products, particularly for ocular hypotensives, with six such FDC approvals between 2001 and 2010 compared with 50 approvals for hypotensive FDC products between 2011 and 2018 (Fig. 1). Of particular note is the authorisation of 15 dorzolamide/timolol FDCs in 2011. The initial combination these actives, Cosopt (Santen), was originally approved in 1998 [42], with a preservative-free single-dose version licensed in 2006 [43]. Generic/hybrid versions followed from 2009 after expiry of market exclusivity with a bulk of such approvals shortly after. In the USA, pharmaceutical companies may bring FDC products to market shortly before generic versions of the single-active ingredient drug enters the market, and consequently extend market exclusivity protection of the single drugs included in the combination [41]. In the EU, however, FDC products are considered to be stand-alone products with an independent period of data and market exclusivity and hence 'generic' versions of FDCs can only be marketed when the period of exclusivity of the FDC has lapsed [4].

Although patients often prefer FDCs as they may simplify drug regimes, be more convenient and reduce personal cost and hence aid adherence to treatment $[39,41]$, there are 
broader financial implications. Such products enable pharmaceutical companies to maintain market share as singleactive agents lose exclusivity protections and generic versions come to market and exert downward pressure on prices. By redirecting demand to FDCs rather than singleagent products, additional financial burden may be placed on public and private health systems [44, 45]. The overall cost-effectiveness of FDCs compared with single-active ingredient medicinal products, particularly in the ophthalmic context, is not fully known and further research on this is warranted.

Topical anti-inflammatory/antibiotic products were the second largest category of FDCs approved, although still very much a minority compared with glaucoma agents, and no new products in this category appear to have been approved since 2003. These combination agents are most commonly employed in the hospital setting for the prophylaxis against infection and inflammation after ocular surgery rather than for use in acute eye conditions [46], although emerging evidence for alternative prophylactic approaches after surgery such as intracameral antibiotics [47] and an expanding role for non-steroidal anti-inflammatory drugs $[48,49]$ may render the market for these FDCs as fairly limited. The approval of 'Mydrane' (lidocaine hydrochloride, phenylephrine hydrochloride and tropicamide; Laboratoires THEA) in 2015, together with the authorisation of Omidria (phenylephrine/ketorolac; Omeros Ireland Limited) by the EMA in 2015 [3], demonstrates an additional interest in the development of pharmacological adjuncts for intraoperative use. It remains to be seen whether the market for combination agents will move beyond treatments for OHT/ glaucoma and peri-operative indications.

Limitations of this study are acknowledged. As a retrospective review of publicly available regulatory approval data, such studies are reliant upon the accuracy and quality of the source data. Although eye drop products are generally easily identifiable from the data source, it is possible that products may have been missed if, for example, products with a different route of administration were authorised for ophthalmic indications. The authors identified two such products (Aprokam and Ximaract, both constitute the active ingredient cefuroxime powder as a solution used for [intracameral] injection) and consider that any additional such cases, if any, that were not identified should not significantly affect the conclusions of this study. The focus of this study on products granted approval by the UK authorities has therefore identified products approved on the national level and through the European decentralised and mutual recognition procedures in which the UK was involved. This approach therefore does not represent a comprehensive study of all ophthalmic products approved for use in the UK ophthalmic setting, as many new ophthalmic products are approved through the panEuropean Centralised Procedure, especially biological therapies such as anti-VEGF agents and other novel therapeutics for ophthalmic disease; details of such products are discussed elsewhere [3]. At the time of writing, the UK remains within the European regulatory system, although the future relationship between the UK and EU is subject to ongoing negotiations [50]. The UK licensing data source reviewed for this study did not include information regarding the legal basis of approval or the type and quality of data provided upon which the regulatory approvals were based, e.g., pharmaceutical and clinical trial data. Public assessment reports are made available following licensing approvals [51], although such reports were not available for all the products identified in this study at the time of data collection. Nonetheless, the products identified in this study represent a considerable portion of the medicines available to treat ophthalmic conditions for patients in the UK, particularly for well-established active substances. Although the focus of the discussion has been on clinical aspects of product approval, it should be emphasised that regulatory requirements for pharmaceutical quality and pre-clinical aspects are also considered in the overall decisions on regulatory licensing approval [52].

\section{Conclusions}

This study has identified ophthalmic medicinal products that received UK MA (outside of the European Centralised Procedure) between 2001 and 2018 and is the first study to collate such data in the public domain. The majority of licences granted were for single-agent products, particularly ocular hypotensives and antibiotic preparations, and almost exclusively for generic ('hybrid') versions of wellestablished active substances. In addition, a trend for increased approvals for FDC preparations is evident, particularly for the treatment of raised IOP where combination therapy is critical for many patients and FDC products may enable advantages for compliance with treatment.

\section{Summary}

\section{What was known before}

- Regulatory approval of medicines requires comprehensive assessment of pharmaceutical, pre-clinical and clinical data by the regulatory authorities, and an assessment of positive benefit-risk balance. The United Kingdom is integrated in the European medicines regulatory network, and medicines can be granted MA on a national or European basis. 


\section{What this study adds}

- This is the first study to collate publicly available regulatory approval data for ophthalmic medicines approved by the MHRA. The majority of licences granted were for single-agent products, particularly ocular antihypertensives, and mainly for generic versions of well-established active substances. There is a trend for increased approvals for FDC products, particularly for the treatment of raised IOP.

Funding The authors received no financial support for the research, authorship and/or publication of this article.

\section{Compliance with ethical standards}

Conflict of interest The authors declare that they have no conflict of interest. Any views expressed in this article are personal and do not necessarily reflect the views or policy of the MHRA or other regulatory agencies.

Publisher's note Springer Nature remains neutral with regard to jurisdictional claims in published maps and institutional affiliations.

\section{References}

1. The licensing of medicines in the UK. Drug Ther Bull. 2009;47:45-7.

2. Regulation (EC) No 726/2004 of the European Parliament and of the Council laying down Community procedures for the authorisation and supervision of medicinal products for human and veterinary use and establishing a European Medicines Agency. Off J Eur Union. 2004;136:1-33.

3. Morgan-Warren PJ. Ophthalmic medicine regulatory approvals through the European Centralised Procedure, 1999-2017: clinical efficacy considerations. Eur J Ophthalmol. 2019. https://doi.org/ 10.1177/1120672119830932 [Epub ahead of print].

4. European Commission. Notice to Applicants Volume 2a; Procedures for marketing authorisation-Chapter 1 Marketing Authorisation. 2019.

5. Khanna B, Chapter 11-Pharmaceutical regulations in european union. In: Vohora DS, editor. Pharmaceutical medicine and translational clinical research. London, UK: Elsevier; 2018. p. 175-213.

6. Van Norman GA. Drugs and devices: comparison of European and U.S. approval processes. JACC Basic Transl Sci. 2016;1: 399-412.

7. Nagata R, Rafizadeh-Kabe JD. Japanese pharmaceutical and regulatory environment. Dialogues Clin Neurosci. 2002;4:470-4.

8. Schwartz R, Loewenstein A. Early detection of age related macular degeneration: current status. Int $\mathrm{J}$ Retin Vitreous. 2015;1:20.

9. Tatham AJ, Weinreb RN, Medeiros FA. Strategies for improving early detection of glaucoma: the combined structure-function index. Clin Ophthalmol. 2014;8:611-21

10. Varma R, Lee PP, Goldberg I, Kotak S. An assessment of the health and economic burdens of glaucoma. Am J Ophthalmol. 2011;152:515-22.
11. Yu J, Asche CV, Fairchild CJ. The economic burden of dry eye disease in the United States: a decision tree analysis. Cornea. 2011;30:379-87.

12. Clegg JP, Guest JF, Lehman A, Smith AF. The annual cost of dry eye syndrome in France, Germany, Italy, Spain, Sweden and the United Kingdom among patients managed by ophthalmologists. Ophthalmic Epidemiol. 2006;13:263-74.

13. https://www.gov.uk/government/collections/marketing-authorisa tions-lists-of-granted-licences. Accessed 1 Nov 2018; reviewed 25 Oct 2019

14. https://webarchive.nationalarchives.gov.uk/20150121214323/ http://www.mhra.gov.uk/Howweregulate/Medicines/ Licensingofmedicines/Informationforlicenceapplicants/ Otherusefulservicesandinformation/Listsofapprovedproducts/Ma rketingauthorisations/index.htm. Accessed 1 Jul 2019.

15. Bourne RR, Taylor HR, Flaxman SR, Keeffe J, Leasher J, Naidoo $\mathrm{K}$, et al. Number of people blind or visually impaired by glaucoma worldwide and in world regions 1990-2010: a meta-analysis. PLoS One. 2016;11:e0162229.

16. Rouland JF, Berdeaux G, Lafuma A. The economic burden of glaucoma and ocular hypertension: implications for patient management: a review. Drugs Aging. 2005;22:315-21.

17. Bremond-Gignac D, Chiambaretta F, Milazzo S. A European perspective on topical ophthalmic antibiotics: current and evolving options. Ophthalmol Eye Dis. 2011;3:29-43.

18. Isenberg SJ. The fall and rise of chloramphenicol. J AAPOS. 2003;7:307-8.

19. Bielory L, Katelaris CH, Lightman S, Naclerio RM. Treating the ocular component of allergic rhinoconjunctivitis and related eye disorders. MedGenMed. 2007;9:35.

20. Council Directive 2001/83/EC on the Community code relating to medicinal products for human use. Off J Eur Union. 2001;311: 67-128.

21. Committee for Medicinal Products for Human Use. Guideline on the investigation of bioequivalence. European Medicines Agency, London. 2010.

22. Committee for Proprietary Medicinal Products. Note for guidance on the clinical requirements for locally applied, locally acting products containing known constituents. European Medicines Agency, London. 1995.

23. Digiuni M, Manni G, Vetrugno M, Uva M, Milano G, Orzalesi N, et al. An evaluation of therapeutic noninferiority of $0.005 \%$ latanoprost ophthalmic solution and xalatan in patients with glaucoma or ocular hypertension. J Glaucoma. 2013;22:707-12.

24. Titcomb LC. Are generic topical prostanoids the way forward in the care of glaucoma patients?-Yes. Eye (Lond). 2013;27:999-1001.

25. Dubois VD. Are generic topical prostanoids the way forward in the care of glaucoma patients?-No. Eye (Lond). 2013;27: $1002-3$.

26. MHRA, Public Assessment Report-Iluvien 190 micrograms Intravitreal Implant in Applicator. 2019. https://products.mhra. gov.uk/?search=iluvien\&page=1. Accessed 1 July 2019.

27. Committee for Proprietary Medicinal Products. Points to consider on application with 1. meta-analyses; 2 . one pivotal study. European Medicines Agency, London. 2001.

28. Medical Products Agency. Public Assessment Report-Aprokam (cefuroxime sodium). 2012. https://lakemedelsverket.se/LMF/La kemedelsinformation/?nplid $=20110407000047 \&$ type $=$ product. Accessed 1 July 2019.

29. Endophthalmitis Study Group, European Society of Cataract \& Refractive Surgeons. Refractive, Prophylaxis of postoperative endophthalmitis following cataract surgery: results of the ESCRS multicenter study and identification of risk factors. J Cataract Refract Surg. 2007;33:978-88. 
30. Gore DM, Angunawela RI, Little BC. United Kingdom survey of antibiotic prophylaxis practice after publication of the ESCRS Endophthalmitis Study. J Cataract Refract Surg. 2009;35:770-3.

31. Purslow C, Davey K, Johnson M, Pietri G, Suri G. Budget impact assessment of Aprokam $(\mathrm{R})$ compared with unlicensed cefuroxime for prophylaxis of post-cataract surgery endophthalmitis. BMC Ophthalmol. 2015;15:72.

32. Medical Products Agency, Public Assessment Report - Ximaract (cefuroxime sodium). 2016. https://lakemedelsverket.se/LMF/La kemedelsinformation/?nplid $=20150410000092 \&$ type $=$ product. Accessed 1 July 2019.

33. Borg JJ, Laslop A, Pani L, Maciulaitis R, Melchiorri D. Reflections on decisions made on the well-established use of medicinal products by EU regulators and the ECJ. Sci Pharm. 2014;82: 541-54.

34. MHRA, Borderlines between medical devices and medicinal products. Medicines \& Healthcare products Regulatory Agency, London. 2013.

35. Racchi M, Govoni S, Lucchelli A, Capone L, Giovagnoni E. Insights into the definition of terms in European medical device regulation. Expert Rev Med Devices. 2016;13:907-17.

36. Zaki M, Pardo J, Carracedo G. A review of international medical device regulations: Contact lenses and lens care solutions. Cont Lens Anterior Eye. 2019;42:136-46.

37. Titcombe L. Are quality standards being reduced as eye drops are classed as devices? Pharm J. 2010;284:633-8.

38. Human Medicines Regulations (SI 2012/1916). UK legislation. 2012.

39. Committee for Human Medicinal Products. Guideline on clinical development of fixed combination medicinal products. European Medicines Agency, London. 2017.

40. Robin A, Grover DS. Compliance and adherence in glaucoma management. Indian J Ophthalmol. 2011;59(Suppl):S93-6.

41. Hao J, Rodriguez-Monguio R, Seoane-Vazquez E. Fixed-dose combination drug approvals, patents and market exclusivities compared to single active ingredient pharmaceuticals. PLoS One. 2015;10:e140708.

42. Cosopt, Summary of Product Characteristics. https://www. medicines.org.uk/emc/product/5113/smpc. Accessed 1 Jul 2019.

43. Cosopt Preservative-Free, Summary of Product Characteristics. https://www.medicines.org.uk/emc/product/5114/smpc. Accessed 1 Jul 2019.

44. Hong SH, Wang J, Tang J. Dynamic view on affordability of fixed-dose combination antihypertensive drug therapy. Am J Hypertens. 2013;26:879-87.

45. Rabbani A, Alexander GC. Out-of-pocket and total costs of fixeddose combination antihypertensives and their components. Am J Hypertens. 2008;21:509-13.

46. Bradshaw SE, Shankar P, Maini R. Topical steroid and antibiotic combination therapy in red eye conditions. $\mathrm{Br} \mathrm{J}$ Gen $\mathrm{Pr}$. 2006;56:304

47. Haripriya A, Chang DF. Intracameral antibiotics during cataract surgery: evidence and barriers. Curr Opin Ophthalmol. 2018;29:33-9.

48. Almeida DR, Johnson D, Hollands H, Smallman D, Baxter S, Eng $\mathrm{KT}$, et al. Effect of prophylactic nonsteroidal antiinflammatory drugs on cystoid macular edema assessed using optical coherence tomography quantification of total macular volume after cataract surgery. J Cataract Refract Surg. 2008;34:64-9.

49. Hoffman RS, Braga-Mele R, Donaldson K, Emerick G, Henderson B, Kahook M, et al. Cataract surgery and nonsteroidal antiinflammatory drugs. J Cataract Refract Surg. 2016;42:1368-79.

50. Breckenridge A, Feldschreiber P. Impact of brexit on UK and EU drug regulation and patient access. Clin Pharm Ther. 2019;105: 923-5.

51. MHRA Public Assessment Reports. http://www.mhra.gov.uk/ public-assessment-reports. Accessed 1 Jul 2019.

52. Committee for Human Medicinal Products. Reflection paper on benefit-risk assessment methods in the context of the evaluation of marketing authorisation applications of medicinal products for human use. European Medicines Agency, London. 2008. 